\title{
Prevalence of common comorbidities among urogynaecological patients
}

\author{
Tomasz Rechberger ${ }^{1}$, Łukasz Nowakowski ${ }^{1}$, Ewa Rechberger ${ }^{2}$, Alicja Ziętek ${ }^{1}$, \\ Izabela Winkler ${ }^{1}$, Paweł Miotła ${ }^{1}$ \\ ${ }^{1} 2^{\text {nd }}$ Department of Gynaecology Medical University of Lublin, Poland \\ ${ }^{2}$ Medical University of Lublin, Poland
}

\begin{abstract}
Objectives: Due to prolonged life expectancy, regardless of the fact that elderly women are more likely to suffer from comorbidities, urogynaecologists worldwide should expect a growing demand for counseling and effective treatment for patients with pelvic floor defects. The aim of the study was to investigate the incidence of popular comorbidities among urogynaecological patients.

Material and methods: The retrospective analysis included clinical data of 4,065 consecutive female patients who underwent surgical treatment in the $2^{\text {nd }}$ Department of Gynaecology at the Medical University of Lublin due to urogynaecological disorders between January 2005 and December 2014. Patients were divided into two groups ( $<65$ years and $\geq 65$ years). The vast majority of patients affected by stress urinary incontinence were treated with mid-urethral slings. Most of patients affected by pelvic organ prolapse underwent reconstructive vaginal surgery with reinforcement using anterior and/or posterior meshes. Statistical analysis was performed using STATISTICA 10.0 PL (unpaired Student t-test, U Mann Whitney, $X^{2}$ test) Results: In both study groups, overweight and obesity were the most common disorders affecting urogynaecological patients ( $72.6 \%$ overall). Furthermore, the elderly patients suffered more often from the most common comorbidities, such as hypertension $(p<0.01)$, coronary artery disease $(p<0.001)$ and diabetes mellitus $(p<0.005)$

Conclusions: Common comorbidities such as overweight and obesity, followed by hypertension and coronary heart diseases, are usual among urogynaecological patients. Changes in lifestyle leading to a decrease in obesity should be considered as an important line treatment when counselling urogynaecological patients.
\end{abstract}

Key words: obesity, urinary incontinence, pelvic organ prolapse, lower urinary tract symptoms, comorbidities

Ginekologia Polska 2016; 87, 5: 342-346

\section{INTRODUCTION}

Urogynaecological disorders which require surgical interventions have received much attention recently. This is mainly due to current demographical trends, which clearly indicate that in the next 30-40 years in developed countries a steady increase in the percentage of elderly people will be observed with the population aged over 85 exceeding $4.3 \%$ in 2050 [1]. This, of course, is a consequence of the increase in female life expectancy. It will also increase significantly the occurrence of associated common comorbidities as well as pelvic floor dysfunctions, either anatomical or functional. In the United States, the age-adjusted surgical rate is almost
64 for gynaecological surgeries per 10,000 female patients aged $\geq 65$ years [2].

Therefore, urogynaecologists worldwide should expect a growing demand for counseling and effective treatment for patients with pelvic floor defects, regardless of the fact that elderly women are more likely to suffer from other comorbidities which may also aggravate preoperative and postoperative lower urinary tract symptoms (LUTS). Some prognoses predict a more than $50 \%$ increase for urogynaecological procedures in the coming years [3]. Recently, a big debate started concerning the standardization of surgical techniques for treatment of pelvic floor dysfunc- 
tions, especially those due to Food and Drug Administration (FDA) statements regarding the use of artificial prostheses in urogynaecology [4]. Surgeons should also remember that advanced age itself, regardless of accompanying comorbidities, will increase the risk of postoperative complications when compared to younger counterparts undergoing the same surgical procedures [5]. We observed in our recent study that cardiovascular diseases (hypertension and coronary artery disease), which could partially increase intra- and postoperative mortality risk, were found among $43 \%$ of patients with pelvic floor symptoms [6].

On the other hand, in the near future there will definitely be a marked increase in demands for operative intervention, even assuming an increase in perioperative and postoperative morbidity and mortality when compared to the younger population.

\section{OBJECTIVES}

The aim of our retrospective study was to analyze the prevalence of common comorbidities as well as clinical indications for the urogynaecological admission of patients to the $2^{\text {nd }}$ Department of Gynaecology at the Medical University of Lublin during the last 10 years.

\section{MATERIAL AND METHODS}

The study protocol was approved by our local institutional ethical committee (Institutional Board Review for the Medical University of Lublin, Poland). This retrospective analysis included clinical data of 4,065 consecutive female patients who underwent surgical treatment in $2^{\text {nd }}$ Department of Gynaecology at the Medical University of Lublin due to various urogynaecological disorders between January 2005 and December 2014. All patients were informed about benefits associated with lifestyle modifications in outpatient clinic. Moreover, all participants were strongly encouraged to follow conservative treatment options, which include lifestyle interventions: weight loss, dietary restrictions, physical exercise, pelvic floor exercises and voiding regimens. Only patients who did not respond to conservative treatment were scheduled to surgery. Indications for surgical treatment were as follows: stress urinary incontinence (SUI) resistant for physiotherapy, symptomatic pelvic organ prolapse (POP, stage III and IV according to pelvic organ prolapse quantification (POP-Q) system), overactive bladder $(O A B)$ syndrome resistant to anticholinergics and $\beta$-3 agonist, and recurrent prolapse after unsuccessful previous surgery. The vast majority of patients affected by stress urinary incontinence were treated with mid-urethral slings (transobturator or retropubic) or Burch colposuspension. The majority of patients affected by symptomatic prolapse underwent: reconstructive vaginal mesh surgeries (anterior and/or posterior meshes depending on the specific clinical situation), vaginal hysterectomy (in the case of additional uterine pathology) with concomitant anterior and posterior colporraphy. In patients with concomitant prolapse and stress urinary incontinence, both procedures were performed at the same time. In sexually inactive elderly patients, Neugebauer Le-Fort colpocleisis was performed after excluding cervical or endometrial neoplasm and detailed explanation concerning this type of surgery. Abdominal sacrocolpopexy was performed in patients with recurrent utero-vaginal prolapse, whereas Botox injections (100 units) were used in women admitted due to overactive bladder syndrome resistant to pharmacotherapy. Bulking agents were used in patients after unsuccessful sling surgery, in whom urethral hypermobility was not present. Body mass index descriptors were used in accordance with classification of World Health Organization [7]. Statistical analysis was performed using STATISTICA 10.0 PL, using the unpaired Student t-test, Mann-Whitney $U$ test, and the $X^{2}$ test, as appropriate $p<0.05$ was considered statistically significant.

\section{RESULTS}

Patients were divided into two groups based on their age. Group $A(<65$ years; $n=2577$ ), and group $B$ ( $\geq 65$ years; $n=1488)$. In total, urogynaecological patients accounted for $13 \%$ of all surgically treated women during the analysed time period. Demographical data on women from both groups are presented in Table 1. Type of surgery and occurrence of common comorbidities in both study groups are presented in Tables 2 and 3.

In both study groups, overweight and obesity were the most common comorbidities affecting urogynaecological patients (72.6\% overall). These were followed by hypertension ( $46.6 \%$ overall), diabetes ( $13.5 \%$ overall) and coronary artery diseases (12.5\% overall). Metabolic syndrome (obesity, hypertension, diabetes and dyslipidemia) occurred more often in elderly patients ( $p<0.001$; U Mann Whitney test).

\section{DISCUSSION}

To our best knowledge this is the biggest cohort of Polish women affected by various urogynaecological problems. In the past ten years, we have observed changing trends in our Department in the primary surgical treatment options in the case of urogynaecological problems, either anatomical or

Table 1. Demographic characteristics of patient groups

\begin{tabular}{|l|c|c|}
\hline Parameter & $\begin{array}{c}\text { Group A }<65 \text { years } \\
(\mathbf{n}=\mathbf{2 5 7 7})\end{array}$ & $\begin{array}{c}\text { Group B } \geq 65 \text { years } \\
(\mathbf{n}=\mathbf{1 4 8 8})\end{array}$ \\
\hline Age (years) (mean; SD) & $53 \pm 7.76$ & $71 \pm 5.36$ \\
\hline BMI $\left[\mathrm{kg} / \mathrm{m}^{2}\right]$ (mean; SD) & $27.8 \pm 4.66$ & $28.2 \pm 4.63$ \\
\hline Parity (mean; SD) & $2.41 \pm 1.08$ & $2.32 \pm 0.84$ \\
\hline
\end{tabular}


Table 2. Type of surgery in patients from both groups

\begin{tabular}{|l|c|c|}
\hline Type of surgery & $\begin{array}{c}\text { Group } \mathbf{A}<\mathbf{6 5} \text { years } \\
(\mathbf{n}=\mathbf{2 5 7 7 )}\end{array}$ & $\begin{array}{c}\text { Group } \mathbf{B} \geq 65 \text { years } \\
(\mathbf{n}=\mathbf{1 4 8 8})\end{array}$ \\
\hline TVM anterior $(\mathrm{n} ; \%)$ & $236(9.0)$ & $148(9.9)$ \\
\hline TVM posterior $(\mathrm{n} ; \%)$ & $170(6.5)$ & $85(5.7)$ \\
\hline TVM and TOT $(\mathrm{n} ; \%)$ & $425(16.0)$ & $212(14.2)$ \\
\hline TOT & $1,285(50.0)$ & $467(31.4)$ \\
\hline Neugebauer LeFort procedure $(\mathrm{n} ; \%)$ & $0(0)$ & $150(10.1)$ \\
\hline Botox injection $(\mathrm{n} ; \%)$ & $114(4.4)$ & $88(5.9)$ \\
\hline Bulking agent injection $(\mathrm{n} ; \%)$ & $56(2.0)$ & $48(3.2)$ \\
\hline TVH with anterior and posterior colporraphy $(\mathrm{n} ; \%)$ & $147(5.7)$ & $185(12.4)$ \\
\hline Burch surgery $(\mathrm{n} ; \%)$ & $52(2.0)$ & $49(3.3)$ \\
\hline Sacrocolpopexy $(l a p a r o t o m y)(n ; \%)$ & $92(3.6)$ & $56(3.8)$ \\
\hline
\end{tabular}

TVM — transvaginal mesh, TOT — transobturator tape, TVH — transvaginal hysterectomy

Table 3. Common comorbidities among patients from both study groups

\begin{tabular}{|c|c|c|c|c|c|}
\hline \multirow[t]{2}{*}{ Comorbidity } & \multicolumn{2}{|c|}{$\begin{array}{l}\text { Group } A<65 \text { years } \\
\qquad(n=2577)\end{array}$} & \multicolumn{2}{|c|}{$\begin{array}{l}\text { Group } B \geq 65 \text { years } \\
\qquad(n=1488)\end{array}$} & \multirow[t]{2}{*}{$p$ value } \\
\hline & Number of patients & $\%$ & Number of patients & $\%$ & \\
\hline Overweight & 1,057 & 41 & 658 & 44.2 & $>0.05$ \\
\hline Obesity & 753 & 29.2 & 485 & 32.6 & $>0.05$ \\
\hline Hypertension & 1,119 & 43.4 & 775 & 52.1 & $<0.01$ \\
\hline Diabetes & 284 & 11.0 & 263 & 17.7 & $<0.005$ \\
\hline Coronary artery disease & 265 & 10.3 & 243 & 16.3 & $<0.001$ \\
\hline Hypothyroidism & 222 & 8.6 & 116 & 7.8 & $>0.05$ \\
\hline Metabolic syndrome & 106 & 4.2 & 91 & 6.1 & $<0.05$ \\
\hline Hyperthyroidism & 98 & 3.8 & 43 & 2.9 & $>0.05$ \\
\hline No comorbidities & 448 & 17.4 & 190 & 12.8 & $<0.01$ \\
\hline
\end{tabular}

functional. In the analyzed period of time, the majority of SUI sufferers were treated with mid-urethral slings. Burch colposuspension was offered only to the patients suffering from SUI in the case of concomitant abdominal surgery. On the other hand, in the last ten years, the surgical treatment of choice for symptomatic pelvic organ prolapse-stages III and IV of POP-Q system (after detailed explanations of all risks) was vaginal reconstructive surgery with syntethic, polypropylene type I meshes [8]. As we have recently published, POP reconstructive mesh surgeries significatly improved self-perceived quality of life in the long-term observation, with a low number of complications (erosions - $6 \%$, postoperative OAB symptoms - 2.7\%) [9]. Moreover, this type of surgery did not deteriorate the sexual life of patients [10]. After the FDA safety statement, the number of mesh surgeries did not decrease in our Department, which is similar to the providers (31\%) who responded in the International Urogynecology Association member survey concerning reconstructive surgery practice patterns [11].
As clearly seen from the above results, as many as $84.3 \%$ of our urogynaecological patients are affected by common comorbidities. The disorders most often encountered are overweight and obesity, which is in accordance with worldwide trends. Overweight and obesity are now the fifth leading risk for global deaths with prevalence rates that continue to rise in most modern western societies. There is much evidence clearly indicating that obesity is directly related to various health problems, such as hypertension, dyslipidaemia, cardiovascular disease (CVD), liver dysfunction, respiratory and musculoskeletal disorders, sub-fertility, psychosocial problems, and certain types of cancers as well as pelvic floor disorders [12]. The possible mechanism by which overweight, and especially obesity, influence pelvic floor anatomy and function include: chronic increase in intra-abdominal pressure, damage to pelvic musculature, nerve damage and associated conduction abnormalities, obesity-related comorbidities (diabetes and diabetic neuropathy, hypertension) and intervertebral disc herniation 
$[13,14]$. It has also been shown in several studies that a weight loss programs (surgical and non-surgical) may be an effective treatment for the management of pelvic floor disorders. It was described that weight reduction leads to improvement in urinary incontinence episodes and quality of life related to pelvic floor symptoms, even if there were no changes in POP-Q system [15]. In one clinical study, overweight and obesity were strongly associated with urinary and faecal incontinence, but there was no association with symptoms of genital prolapse. The increase in BMI was positively correlated with the frequency of urinary incontinence. Obesity was not strongly associated with prolapse symptoms; however, women with pelvic organ prolapse had an increased risk of Ul occurrence [16].

Since obesity has a negative impact on both pelvic organ prolapse and urinary incontinence, successful weight reduction is very likely to improve these symptoms. Urogynaecologists should consider weight loss strategy as part of additional effective treatment, regardless of pelvic floor muscle training, because this may obviate the need for recurrent interventions in the future. In a certain epidemiological cross-sectional study, which involved 7,949 community-dwelling women, a significant association was found between obesity and urinary incontinence, with odds ratios for the presence of UI as high as 1.6 per 5 units increase in BMI [17]. Moreover, there is much clinical evidence showing that increased body weight is a strong risk factor for hypertension. On the other hand, a meta-analysis of randomized controlled trials clearly shows that weight loss is important for the prevention and treatment of hypertension since it was found that every kilogram of weight loss was associated with reductions in blood pressure $-1.05 \mathrm{~mm} \mathrm{Hg}$ systolic and $-0.92 \mathrm{~mm} \mathrm{Hg}$ diastolic [18]. Additionally strong evidence exists that a lifestyle intervention programs with the goals of at least a $7 \%$ weight loss and at least 150 minutes of physical activity per week, was more effective than metformin in prevention or delaying the development of diabetes which was found to be the $4^{\text {th }}$ most commonly encountered comorbidity among our urogynaecological patients. Weight reduction decreased the incidence of diabetes by $58 \%$, whereas with metformin alone, by only $31 \%$, compared with placebo. This difference was statistically significant [19]. In a large population-based, cross-sectional study it was found that hypertension is correlated positively with storage and post micturition symptoms in women. This may be due the effects of cardiovascular and renal physiology; however, certain groups of the antihypertensive drugs can also have a negative influence on lower urinary tract symptoms [20]. Results of the Taiwan Longitudinal Survey of Aging revealed that women with hypertension had a significantly higher risk of UI compared to patients without hypertension. Moreover, BMI was a substantial risk factor for the presence of urinary incontinence [21]. Recent evidence also suggests that arterial hypertension is observed in $56 \%$ of women aged $\geq 50$ years suffering from urinary incontinence. Moreover, two-third of the participants were patients with overweight or obesity and both of these factors were associated with presence of urinary incontinence.

The strength of our study were sample size and duration of observation, however there is no doubt that the major limitations are the retrospective design and lack of professional assistance in lifestyle modifications advised to our patients in order to cure or decrease the severity of urogynaecological symptoms.

\section{CONCLUSIONS}

Common comorbidities are frequently encountered among urogynaecological patients, with overweight and obesity being the leading conditions with the prevalence rate as high as $71 \%$ of analyzed women. These health issues are modifiable and there is a need to educate patients in a healthy life style. Since weight excess may presumably deteriorate the effect of surgical intervention, patients should be informed that a weight loss programs could be considered as an integral part of treatment of urogynaecological disorders, with a presumed beneficial effect not only on the final outcome of urogynaecological surgery but also on general well-being. Changes in lifestyle, mainly increasing physical activity and promoting a balanced diet, can effectively decrease the obesity epidemic and the risk of certain comorbidities, as well as urogynaecological symptoms observed in women.

\section{REFERENCES}

1. Department of Health and Human Services, Administration on Aging Aging statistics. http://www.aoa.gov/aoaroot/aging_statistics/index. aspx. Accessed August 20, 2013.

2. Erekson EA, Ratner ES, Walke LM, Fried TR. Gynecologic surgery in the geriatric patient. Obstet Gynecol. 2012, 119, 1262-1269.

3. Wu JM, Hundley AF, Fulton RG, Myers ER. Forecasting the prevalence of pelvic floor disorders in US women: 2010 to 2050. Obstet Gynecol. 2009, 114, 1278-1283.

4. Clemons $\mathrm{J}$, Weinstein M, Guess MK, [et al.]; on behalf of the AUGS Research Committee. Impact of the 2011 FDA Transvaginal Mesh Safety Update on AUGS Members'Use of Synthetic Mesh and Biologic Grafts in Pelvic Reconstructive Surgery. Female Pelvic Medicine \& Reconstructive Surgery. 2013, 4, 191-198.

5. Sung VW, Weitzen S, Sokol ER, [et al.]. Effect of patient age on increasing morbidity and mortality following urogynecologic surgery. Am J Obstet Gynecol. 2006, 194, 1411-1417.

6. Rechberger T, Miotła P, Futyma K, [et al.]. Risk factors of pelvic organ prolapsed in women qualified to reconstructive surgery - the Polish multicenter study. Ginekol Pol. 2010, 81, 821-827.

7. "BMI Classification". Global Database on Body Mass Index. World Health Organization. 2006. Retrieved July 27, 2012. http://apps.who.int/bmi/index.jsp?introPage=intro_3.html.

8. Bump RC, Mattiasson A, Bø K, Brubaker LP, [et al.].The standardization of terminology of female pelvic organ prolapse and pelvic floor dysfunction. Am J Obstet Gynecol. 1996, 175, 10-17.

9. Bartuzi A, Futyma K, Kulik-Rechberger B, [et al.]. Self-perceived quality of life after pelvic organ prolapse reconstructive mesh surgery: prospective study. Eur J Obstet Gynecol Reprod Biol. 2013, 169, 108-112. 
10. Bartuzi A, Futyma K, Kulik-Rechberger B, [et al.]. Transvaginal Prolift $\left({ }^{\oplus}\right)$ mesh surgery due to advanced pelvic organ prolapse does not impair female sexual function: a prospective study. Eur J Obstet Gynecol Reprod Biol. 2012, 165, 295-298.

11. Ghoniem G, Hammett J. Female pelvic medicine and reconstructive surgery practice patterns: IUGA member survey. Int Urogynecol J. 2015, 26, 1489-1494.

12. Kyrou I, Randeva HS, Weicken MO. Clinical Problems Caused by Obesity. In: De Groot LJ, Beck-Peccoz P, Chrousos G, [et al.] (eds.). Endotext [Internet]. South Dartmouth (MA): MDText.com, Inc. 2014 Apr 24.

13. Hannestad YS, Rortveit G, Daltveit AK, [et al.]. Are smoking and other lifestyle factors associated with female urinary inconti-nence? The Norwegian EPINCONT Study. BJOG. 2003, 110, 247-254.

14. Whitcomb EL, Horgan S, Donohue MC, [et al.]. Impact of surgically induced weight loss on pelvic floor disorders. Int Urogynecol J. 2012, 23, 1111-1116.

15. Gozukara YM, Akalan G, Tok EC, [et al.]. The improvement in pelvic floor symptoms with weight loss in obese women does not correlate with the changes in pelvic anatomy. Int Urogynecol J. 2014, 25, 1219-1225.
16. Uustal Fornell $\mathrm{E}$, Wingren $\mathrm{G}$, [et al.]. Factors associated with pelvic floor dysfunction with emphasis on urinary and fecal incontinence and genital prolapse: an epidemiological study. Acta Obstet Gynecol Scand. 2004, 83, 383-389.

17. Brown JS, Seeley DG, Fong J, [et al.]. Urinary incontinence in older women: who is at risk? Study of Osteoporotic Fractures Research Group. Obstet Gynecol. 1996, 87, 715-721.

18. Neter JE, Stam BE, Kok FJ, [et al.]. Influence of weight reduction on blood pressure: a meta-analysis of randomized controlled trials. Hypertension. 2003, 42, 878-884.

19. Knowler WC, Barrett-Connor E, Fowler SE, [et al.]. Diabetes Prevention Program Research Group. Reduction in the incidence of type 2 diabetes with lifestyle intervention or metformin. NEngl JMed. 2002, 346, 393-403.

20. Wang $\mathrm{Y}, \mathrm{Hu} \mathrm{H}, \mathrm{Xu} \mathrm{K}$, [et al.]. Prevalence, risk factors and the bother of lower urinary tract symptoms in China: a population-based survey. Int Urogynecol J. 2015, 26, 911-919.

21. Chang $\mathrm{KM}, \mathrm{Hsieh} \mathrm{CH}$, Chiang $\mathrm{HS}$, [et al.]. Risk factors for urinary incontinence among women aged 60 or over with hypertension in Taiwan. Taiwan J Obstet Gynecol. 2014, 53, 183-186. 